\title{
Change Detection and Prediction of Urmia Lake and its Surrounding Environment During the Past 60 Years Applying Geobased Remote Sensing Analysis
}

\author{
K. Valizadeh Kamran ${ }^{1 *}$, B. Khorrami ${ }^{2}$ \\ ${ }^{1}$ University of Tabriz, Faculty of Planning and Environmental Sciences, Tabriz, Iran - Tabrizrsgis@ Gmail.com. \\ ${ }^{2}$ DEU, Department of GIS, The Graduate School of Natural and Applied Sciences, Izmir, Turkey - Behnam.Khorrami@ Yahoo.com.
}

Commission VI, WG VI/4

KEY WORDS: Urmia Lake, Geospatial Information System, Remote Sensing, Change Detection.

\begin{abstract}
:
The gradual depletion of Urmia lake has been a challenge in both national and international scale during recent years. In recent decades the imprudent industrial development accompanied by continuous use of groundwater aquifers has been one of the most pivotal reasons for this crisis. Water level monitoring and detection of its changes within Urmia lake as well as the surrounding environment in the past 60 years integrating GIS, Remote sensing and photogrammetric methods is the main goal for this study. In order to accomplish this, Aerial Photogrammetry images and derived topographic maps from them for the year 1955, Digital Elevation data, quantitative and qualitative information regarding water wells and lake Urmia respectively and finally remotely sensed images of Landsat TM, ETM+ and OLI sensors were used. The temporal range for the study was set to 60 from the year 1955 to 2014. Scrutinizing 12 images relating to different periods, vast changes in both area and perimeter of the lake were detected. Based on the results, the lake area has decreased from 451800 hectares in 1955 to 89730 in recent years due to various causative factors. It is also found that the highest water recession, which caused increasing coastal salty areas, has been occurred in the southern parts of the lake. While the receding water level of the lake has a deep correlation with the increasing agricultural activities around the lake, it has a reverse relation with the lake water EC. These fluctuations can be detrimental to the environment, economy and society. Looking at the changes in lake Urmia, if the current situation keeps on and no drastic measures are taken, turning into a salt land, the Lake would be completely disappeared till 2033.
\end{abstract}

\subsection{Introduction}

The salty Urmia lake (Chichest) is one of the world's salt bodies which is known as a great fortune and one of the environmentally sustainable factors of northwest Iran, has had its own economic, cultural and environmental merits for the region during different periods of the history, from ancient times up to now. Unfortunately, the heedless measures taken by human beings as well as imprudent interferences with the environment has made this blessing to be disappeared gradually. The white spots emerged on the lake and the attachment of some of its islands to the coastal land due to decreasing water level are considered as signs of the drying crisis (figure1). Increased water salinity and lake recession has had detrimental impacts on the lake such as decreasing seeds of Artemia and salinization of the surrounding lands (Stappen G. et al,2001 page 133). Satellite image analysis overtly shows the augmentation in the area of the salt lands around the lake and a severe decline in lake's area. The point is that if the existing drying process keeps on by the current trend and no effective measures are taken a huge body of salt would be left after the process ends which can be very detrimental to the environment of the whole region leaving incurable problems. Taking into account the agricultural economy of the region, it can be estimated that the salty dusts caused by heavy winds would destroy both the economy and nature of the region and neighbouring regions which would cause social problems like poverty, unemployment and migration. The circulating salt would be deposited in the environment leading to the salinization of surface, irrigation and finally ground waters and farm lands. The dried lake would also have other impacts such as outbreak of diseases, destroying of the buildings and infrastructures, climate change and extinction of herbal and animal species whose life depends on the lake's life. Regarding the importance of the issue, the current research aims to apply field survey, maps, aerial and satellite images information with the aid of remote sensing and GIS sciences in a 60 -year period to investigate the lake's water and area fluctuations as well as the green coverage changes quantitatively. It also seeks to conduct qualitative analysis of water salinity (EC index) to unearth the possible relations between dryness of the lake and changes in vegetation coverage and salt lands. At the end, the expected time for the onset of the crisis is going to be declared based on the results in order to soothe the wrath of the nature triggered by death of the lake.

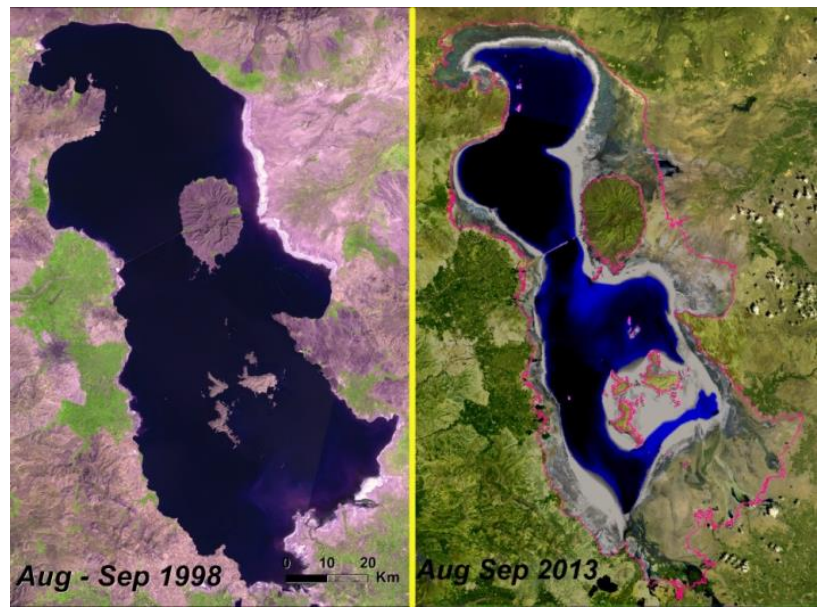

Figure 1. Satellite images of Urmia Lake between Summer 1998 and 2013.The red line shows the boundary of the lake in the year 1998 
The science and technology of remote sensing specially image processing has made it feasible to perform wide range monitoring and comprehensive studies about it. Remote sensing images and methods are completely economical-friendly which provide appropriate accuracy regarding the given area and purpose. Depending on the type of satellite and its sensors, remotely sensed images have got different resolutions. In this study, according to the required temporal and spatial information, aerial photogrammetric data, the sensors TM, ETM+ and OLI of Landsat were used to be processed by Idrisi, Photomod ENVI, Matlab and ArcGIS.

A number of researches on the use of satellite data have been done all around the world to derive coastline maps and monitoring coastal environments of lakes. Most of the salt lakes in Asia, Mexico, Spain, the Soviet Union and the central America have been disappeared due to excessive use of groundwater for agriculture (Alcocer and. Escobar,1996 page55). Field measurements of the then and now water level and deduction of transpired changes, coastline tracking from aerial photos and topographic maps and comparing it with the historical data is one of the common ways in change detection of coasts (Fenster et al,1993 page 147). Integrating Landsat TM and ETM+ images with TOPEX dataset, the water level change of the Lake was estimated about 3 meters by Alesheikh et al (2005:9).

Rasouli and Abbasian(2009) found meaningful difference in the lake's water level during 35 years (1970-2004). In a research on defining the main factors affecting Urmia lake water decline, Rezaei et al (2012), investigated all the parameters relating to water level fluctuations in the lake using MODIS satellite images and remote sensing spectral indices from 2000 to2011 and showed that the coastlines had faced noticeable recession during the study period in the east specially in the southeast of the lake where the lake's max and min water level had declined severely. El Gammal and Salem (2010), studied the influence of the physical phenomena around Nasser lake in Egypt. They realized that morphological structures (mainly faults), weather, topography and sand movements impact deeply the elevation of water, shape of the lake and also its morphological evolution in time. Wasige (2013) applied multitemporal remotely sensed images and GIS to analyze data derived from Landsat TM to study land use changes with the aim of achieving a sustainable development policy for the decision makers in the coastal region in South Korea. Xiuwan (2002), increased both the accuracy and quality of the land use change processing using multi-temporal images adding some auxiliary data including topographic maps, slope, aspect, lithology, soil, hydrology, transportation network, vegetation coverage etc. In another study, the historic and current remote sensing data were used for the assessment of the current situation of Lake Koroneia as well as its destruction rate in Greek. GIS and Remote sensing data, as the main source of information, were used widely to analyse and visualize them. Using secondary data, visual interpretation and expert science through GIS, the results of the supervised classification and post-classification methods in land use change detections improved. On the other hand, the integrated remote sensing and GIS process, led to a $10 \%$ increase in accuracy of the results (Alexandridis, 2007). Integrating remote sensing and GIS, provides precious information about the type and the spatial distribution of land cover changes. In a study in Sri Lanka, detection and monitoring of the wetlands degradation, related to extended agricultural activities, were done with the help of GIS and RS. The relation between wetlands' stance and human livelihood was discovered for the planning and managerial goals (Rebelo et al,2009). Applying RS and GIS, Zhang (2011), offered a comprehensive method for estimating and analysing the 34-year long water storage changes of the lake Nambo located in the central Tibetan Plateau. Satellite images from 1976 to 2009 accompanied by the bathymetry data were used to estimate the transpired changes in the lake's surface area and water storage. He concluded that combining the resulted information with the $3 \mathrm{D}$ profiles of the lake, the exact storing capacity of the lake can be estimated. The core of the previous studies was the change detection of the coastlines with no consideration of the changes occurred in surrounding areas and interactions of causative factors. So in this research, an integrated GIS-RS approach was applied to provide a thorough insight of changes in Urmia lake and its surrounding areas with the aim of giving a hand to the monitoring and management of the lake.

Climate change has a noticeable influence on rainfall patterns, runoff and available water resources. The fast-rate degradation of Urmia lake in recent years has gone hand in hand with the decreasing discharge of the north-western rivers flowing to the lake. Establishing multitudes of dams over these rivers with no environmentally acceptable logic have contributed to this event (Fig 2). On the other hand, the expansion of farmlands around the lake, intemperate use of surface and groundwater resources and digging up of thousands of wells within its watershed area have also intensified this problem. Declining water level of the lake has led to the emergence of wide range of salt lands in the region which can be very hazardous in case of any prospective wind storm (Ahmadzadeh,2006). Considering the direct relation of water EC and water dissolved salts, it's very important to measure water EC to do quality assessment. The more the dissolved ions in water, the higher the level of water EC (Thies and Bendix,2011).

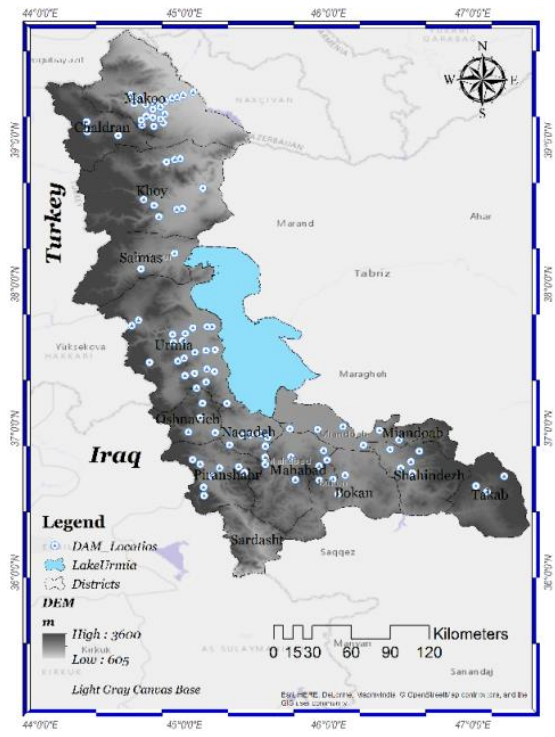

Fig 2. Spatial Distribution of dams within West Azerbaijan province, West and South of Urmia lake.

In addition to physical and geometrical investigations, quality index of the lake's water which is seen as a sign of water salinity degree, included in the analysis. Finally considering the trend of the changes, it's possible to investigate its aftermaths in the region and also to predict the future changes. The study parameters regarding Urmia lake fluctuations are as follow: -Lake's surface water fluctuations -Groundwater fluctuations around the lake -Increase of wells around the lake -Spatial development of salt lands and farmlands around the lake 


\section{-Changes in water EC of the lake}

In order to examine the role of different phenomena in drying process of the lake, the change detection method was used. Performing some of the required corrections including radiometric and atmospheric corrections is essential prior to the image processing and change detection. The images have to be also calibrated and normalized in this stage. For images to be spatially coincided, the geometric correction is a must. All the remote sensing information concerning the region such as satellite images, aerial photos and thematic maps should be fused to be able to detect changes in the region. Since it's highly trustworthy, the Supervised classification method was used in this work. The number of classes in this method is defined by the goal of the study and expert knowledge. Maximum Likelihood and Minimum Distance techniques used in this method, classify images based on the maximum likelihood or the least spectral difference between pixels considering the spatial pattern of the samples and training classes defined by the classifier. The results of this method, which is also called PixelBased classification, may not be accurate due to some topographic or atmospheric noises happened in multispectral images. On the other hand, the allocation of each pixel to one class is not always logical because in some cases a pixel contains spectral information of some ground features so a mixture of land cover information exists in it(Hinton,1996). In situations like these, it's recommended to take benefit of SubPixel Classification texhnique to take over this problem. Frequency of Endmembers suggested by the classifier can be defined in this method using the reference spectrum (Richrds, 2013). According the above mentioned principals, in order to increase the accuracy of the image classification, a conceptual model of decision-tree algorithm as well as the Mixture Tuned Matched Filter(MTMF) technique introduced by Boardman were used to extract the expected information needed for analyses of the Lake's situation (Goudarzimehr et al, 2014).

\subsection{Materials and Methods}

In the current study, to detect the changes of Urmia lake and analyse its dryness, first the photogrammetric photos were interpreted then subpixel classification was conducted on the satellite images and consequently change detection maps were created. At the second stage, the causative parameters of the changes were studied. Data used in this work are: Aerial photos and Topographic map for the year 1955(figure 3), Landsat 5,7 and 8 images (figure 4), Wells' information around the western parts of the lake (figure 10), DEM of the lake, Lake's water quality data (figure12), Bathymetry and Hydrography of the lake's bottom and its surrounding area (figure 13), runoff data of the stream network, precipitation data and population statistics of the region.

\section{Findings}

Integrating historic data, aerial photos and satellite images for the years 1955,1985,2007 and 2014 and based on the land realities and photo interpretation principals, Land use maps of the study area for the last 5 decades were created. The procedure of the work at this step has been illustrated in Fig 5.
Fig 3. Historic Data of Lake Urmia Used in this Study. Topographic map 1956 (right) and Mosaics of Arial photos 1956 (left)

Fig 4. Composite colour image of the lake for the year 2013 , Landsat 8

Fig 5. Flow Chart for Deriving Land Use Map of the Study Area for the Year

Landsat images for the years $1985,2007,2014$ were used to do change assessments. Applying Geometric and Radiometric corrections on the images, the boundary of the lake and land cover classes were extracted (figure 6). Results of the classification were assessed in GIS. Overall accuracy and Kappa index are 93\% and $90 \%$ respectively which prove the suitability of the used method. According to the results obtained by comparing land use changes (figure 7), it is found that the area of the lake has decreased by $80 \%$ while the area of the salt lands showed $70 \%$ increase over the last 50 years. On the other hand, agricultural activities around the lake showed noticeable increase which has doubled during that time period. Based on the figure, the descending trend of the lake's area shows severe decrease over last 7 years so that the area of the lake has been reduced about 300600 ha from 2007 to 2014 while the overall decrease of the area during the whole study time is about 362100 ha which is a sign of critical stance of the lake during the last 7 years. In other words, the changes in the past decade is about 6 times more than the changes during the last 50 years. 


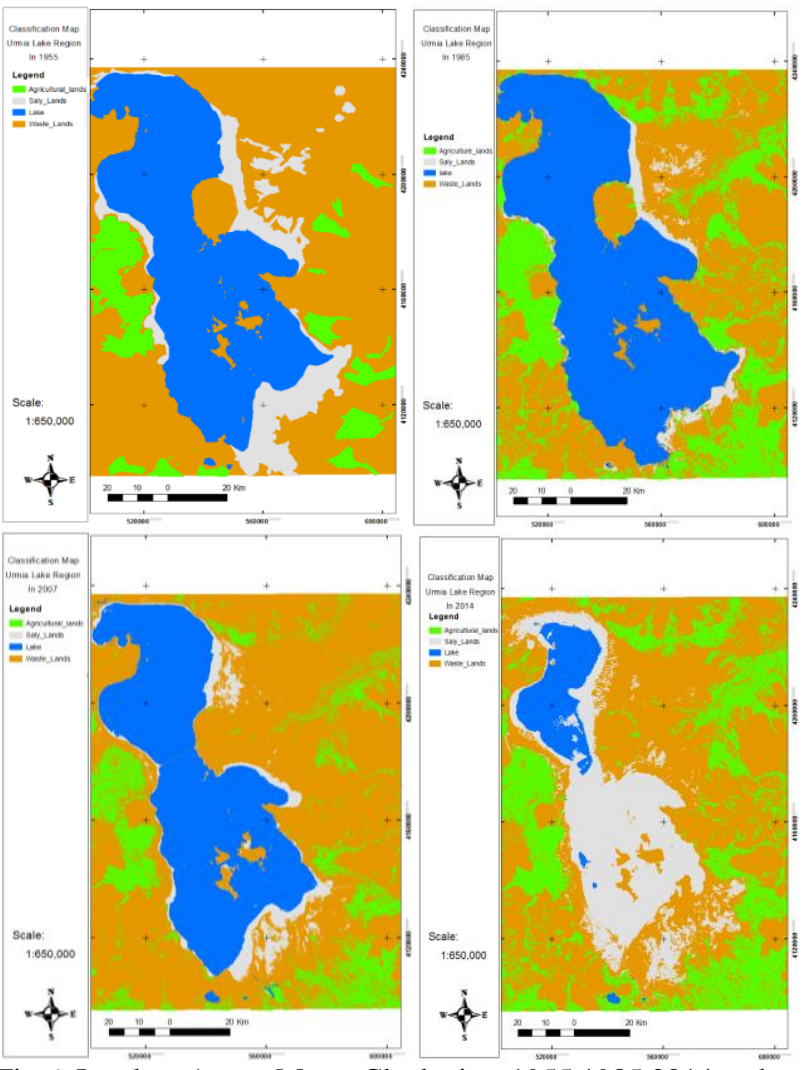

Fig 6. Land use/cover Maps. Clockwise: $1955,1985,2014$ and 2007.

The detected changes also showed 150300 ha increase in agricultural lands while this increase is just 39700 ha for the last 7 years. This indicates that the ascending trend of the agricultural activities in the region has doubled during recent years in comparison to the whole period. Hence, imprudent economical activities in recent years has been an effective factor in overuse of groundwater resources. Construction of multitudes of dams within the watershed of the lake has intensified the decreasing rate of the entering waters into the lake which has led to gradual death of the lake. Change detection maps of the lake are shown in figure 8.

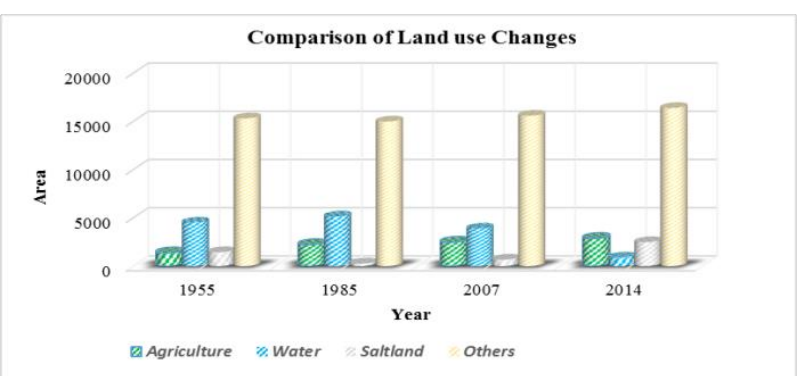

Fig 7. Comparison of the Land Use Changes from 1955 to 2014

Fig 8. Land use change detection maps: Left (1955-1985), Centre (1985-2007), Right (2007-2014).

The water level changes of the lake suggest that the lake's water has decreased from $1276 \mathrm{~m}$ in 1986 to $1270.5 \mathrm{~m}$ in 2014. Based on the information provided by the Census Bureau of the country, the population growth rate has increased about 8 times in recent 50 years in the region with the continuous descending trend in rural population from 1997 up to now. Consequently, urban areas and metropolitans has increased in population in recent years which have had detrimental effects on water resources. Another effective factor in the crisis of the lake is the establishing of hundreds of dams over rivers. Studies show that the runoff of the rivers in the estuaries has declined considerably during the study period (figure 9).

Fig 9. The comparison between water level of the lake and inlet and outlet water of the Dams.

Uncontrolled construction of hundreds of dams and excessive use of groundwater aquifers for different uses including domestic, industrial and agricultural purposes have been very effective in water table fall as well as decrease of the lake's water feed form surface and underground currents. According to the data given by the West Azerbaijan Branch of the Regional Water Company, 20682 number of wells exploited in the western area of the lake between 2002 and 2008. regarding the number of previous wells, the total number of the active wells in the region exceeds 65000 (Figure10).

According to figure 11, groundwater level of the region has declined between 13 to 24 meters during last 10 years (20042014). Over-pumping groundwater aquifers for agricultural uses had been the main causative factor for this event. Based on the available data, about 30722 ha of barren lands in the region have been transformed to land uses with high level of water consumption to take the economic benefits without considering the environmental side effects. Due to these measures, groundwater resources declined severely and surface waters flowing into the lake were blocked. 

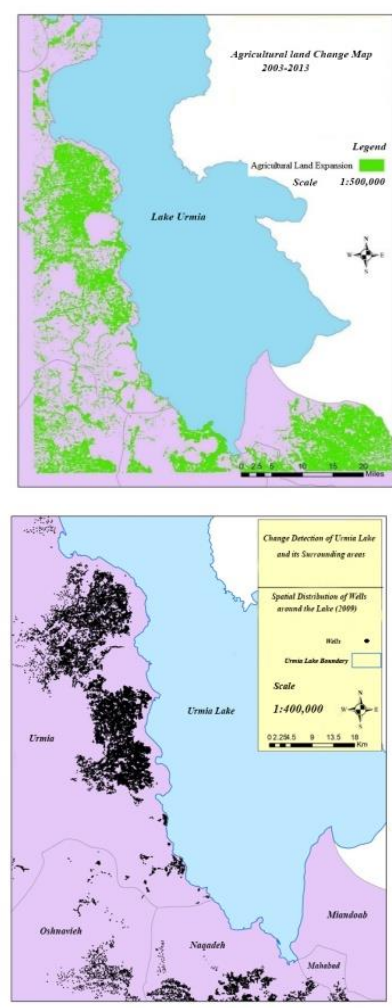

Fig 10. Distribution of the active wells used for agricultural purposes in 2008, West of the Lake(Right), Development of the agricultural lands from 2004 to 2014 (Left).

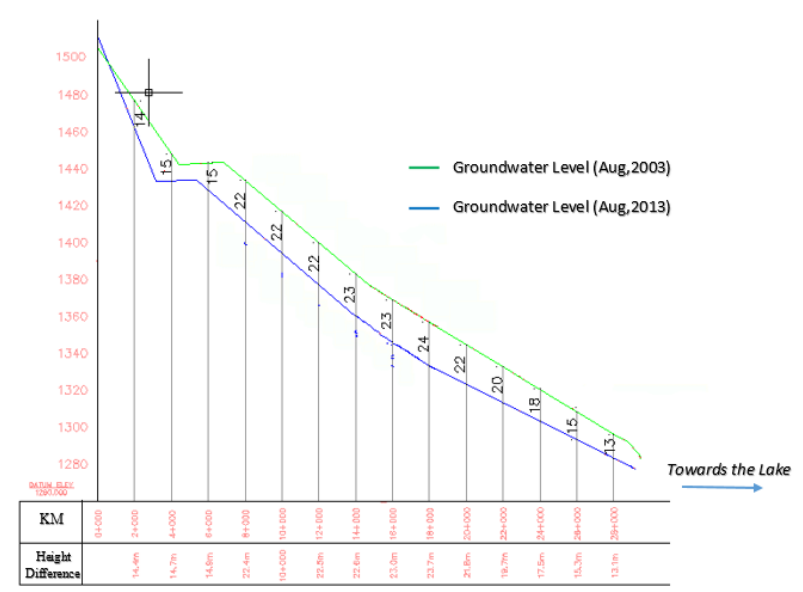

Fig 11. Longitudinal Profile of Groundwater Level Fluctuations of Lake Urmia's Surrounding area during 2003 to 2013.

Analysing water salinity index (EC) of the lake, it is found that the salinity index which is related to water concentration, had
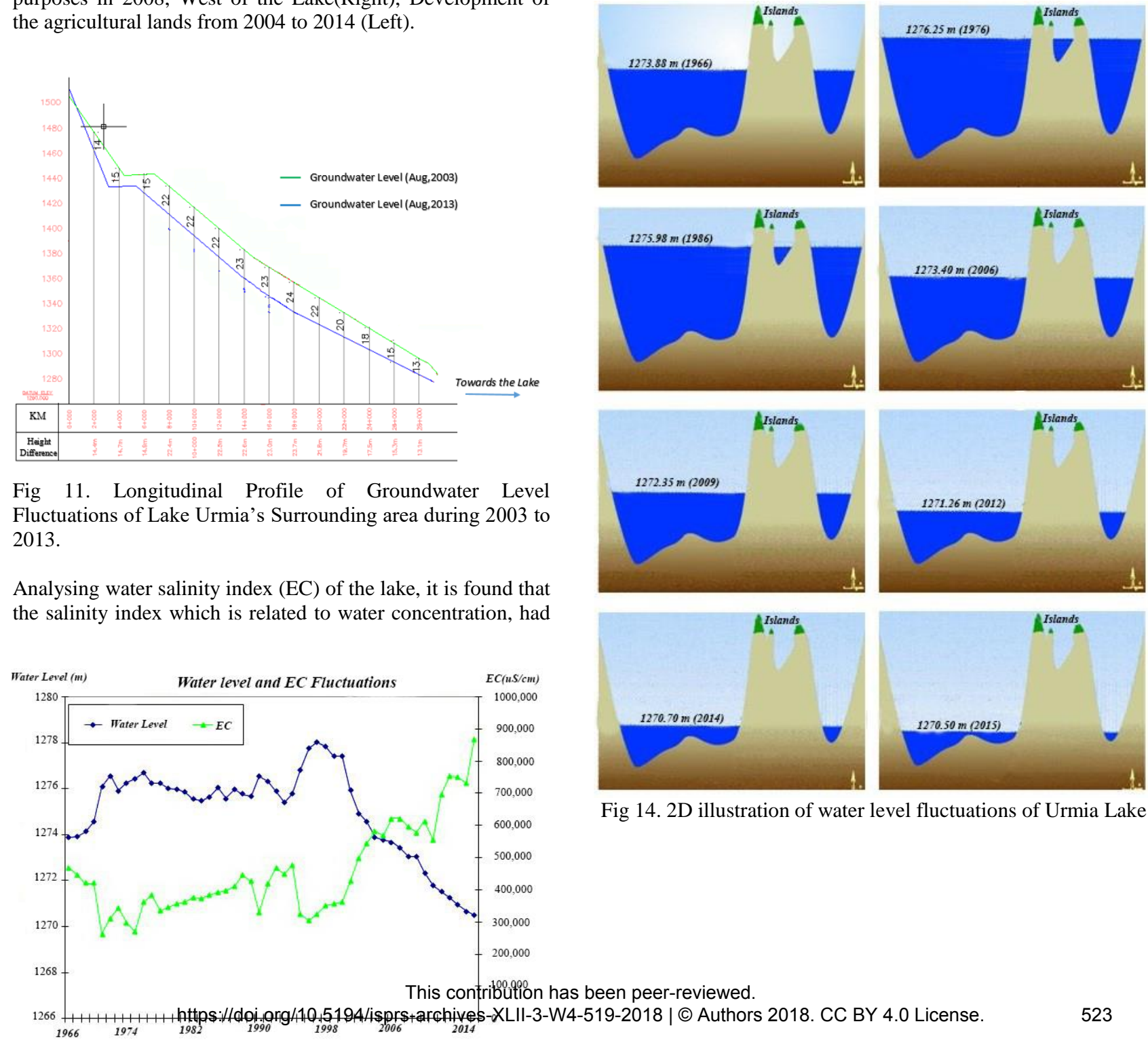

Fig 13. Topographic maps for the lake's bottom and surroundings
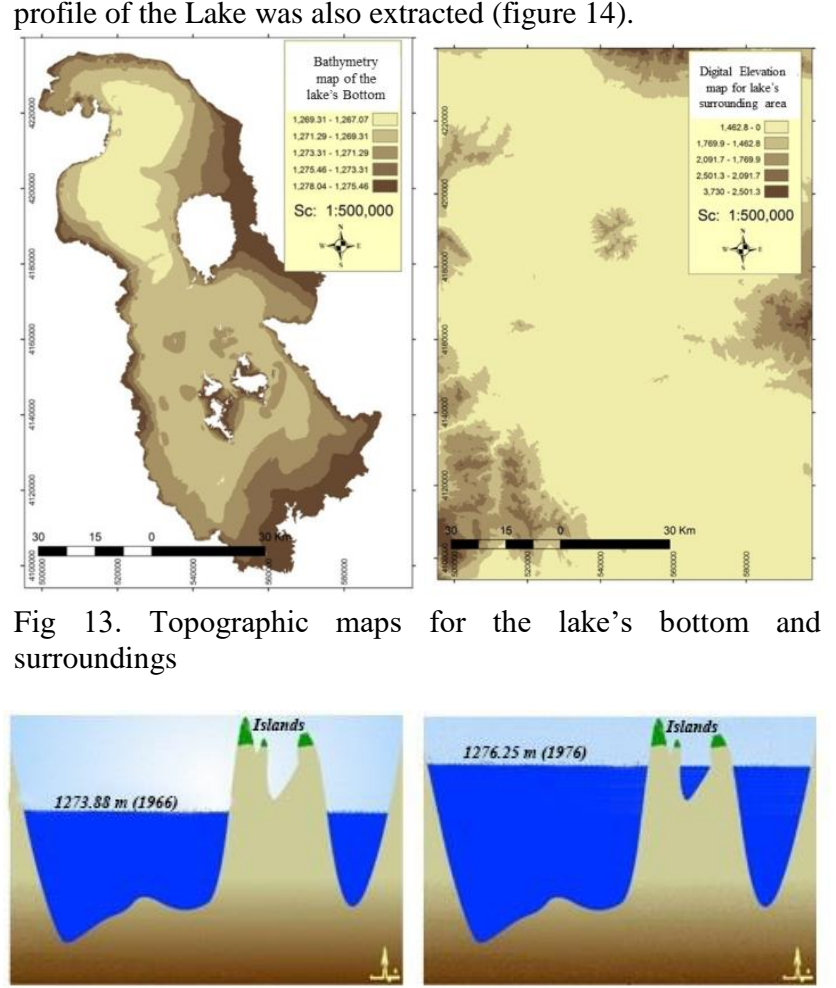

had increasing trend over time. Looking at the figure 12 , it is impact on water salinity index.

Fig 12. Water Level and EC Fluctuations of Lake Urmia: Reverse Overlay of the Quantitative and Qualitative Parameters

The bathymetry and topographic maps of the study area were also created using elevation data and hydrography information profile of the Lake was also extracted (figure 14).

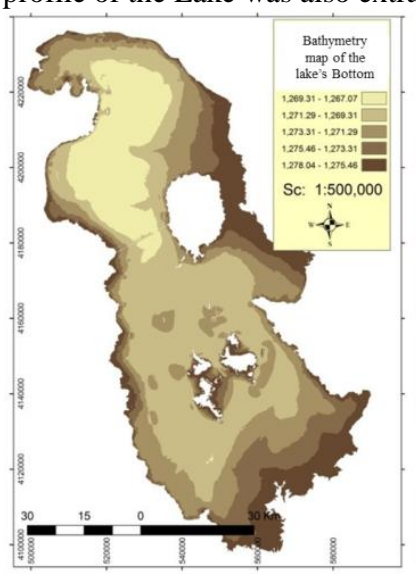

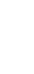




\section{CONCLUSION}

The salty lake of Urmia, is known as one of the world's natural heritages and also one of the most important stabilizing elements for the west of the country. Having got numerous economic and environmental merits, Urmia lake have been facing many crucial challenges in recent years which have led to the detriment of the lake and its environment with incurable damages left behind.

In the present study, all the available information and data including maps, photogrammetry data and satellite images were used to study the changes in area, extent and density of green coverages and land uses around Urmia lake applying RS and GIS over last 60 years. Auxiliary data and information gathered and added to the analysis in order to study the parameters affecting the lake's death such as groundwater data, streams' runoff data, wells information and bottom topography of the lake. Results uncovered the depth of the crisis in the region where about 362100 ha of the area of the lake has been dwindled during last 50 years which is equivalent to $80 \%$ of the lake's area. On the other hand, the salt lands show an increase of about $70 \%$ in area at the same period. Agricultural activities and the farmlands area in the region have also doubled. It is also found that the runoff rate of the main rivers supplying water to the lake has been decreased by $35 \%$ over last 50 years. Digging hundreds of wells around the lake is another reason for the death of the lake. Spatial distribution analyses of the wells showed that the number of wells in the western parts of the lake has been increased by 20682 wells per 10 years. Groundwater level showed min $13 \mathrm{~m}$ and max $24 \mathrm{~m}$ fall from 2004 to 2014 . To detect the relations between water quality and lake's dryness, EC of the lake was studied. Comparing water salinity and water level graphs, it's deducted that over last 20 years the salinity level of the lake has increased continually keeping its reverse relation with water level of the lake. Overall, taking the current trend of water level fluctuations into account, it's clear that the drying process of the lake has continued swiftly in the last 20 years under the contributing pressure of the climate, population and economy of the region. Running regression models suggest (as shown in figure 15) that the lake will disappear entirely until 2034 leaving a complete salt land in the region which may be very harmful to the environment and the living society of all the neighbouring regions.

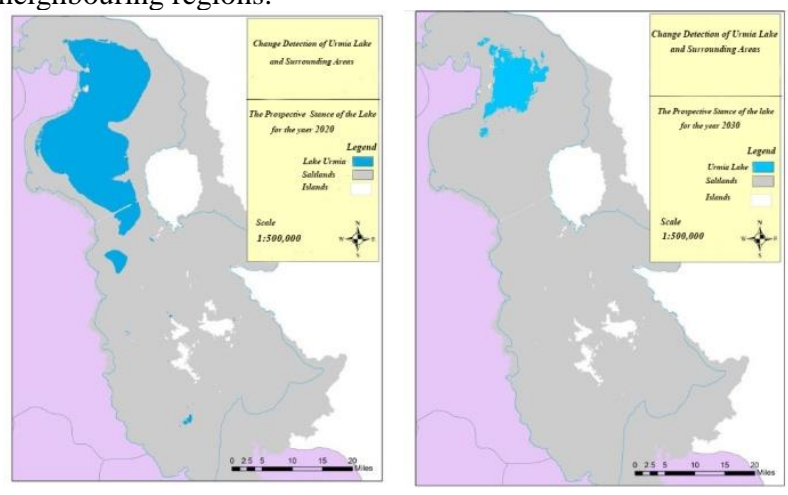

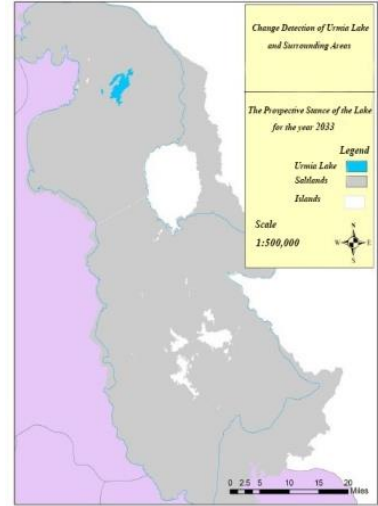

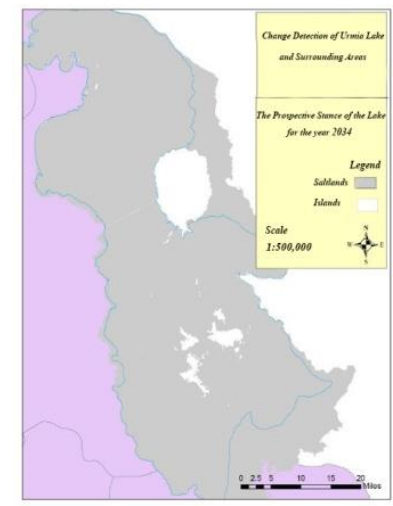

Fig 15. Illustration of the predicted situations of the lake. Clockwise: 2020,2030,2034 and 2033

\section{REFERENCES}

Alesheikh, A., Alimohammadi,A and Qorbanali,A., Monitoring coastal lines of Urmia lake using Remote sensing, Geographic Sciences,1384,pages 9-25.

Ahmadzadeh,B., Defining the equation of the effective parameters in Urmia lake's water level and salinity fluctuations, West Azerbaijan Regional Water Company,1385, Volume 1.

Rasouli,A and Abbasian,Sh., Elementary Time Series Analysis of Water Level of Urmia Lake, Geography and Planning, 1388,no 28,pages137-164.

Rezaei,M., Valizadeh Kamran,Kh., Rostamzadeh,H and Rezaei,A. The Efficiency Assessment of MODIS Data for Drought Estimation (Case Study: Urmia Lake Watershed), Geography and Environment Sustainability,1391, Volume2, No 5, Pages37-57.

Goudarzimehr, S., Alavipanah,K and Darvishi,A. Alteration Mapping Based on Mixture Tuned Matched Filtering Method and with Use of Spectral Images, Natural Geography Researches,1393, No45,Pages 21-38.

Alcocer, J. and E. Escobar, Limnological regionalization of Mexico Lakes \& Reservoirs, Research \& Management, 1996. Vol. 2, pp. 55-69.

Alexandridis, T.K., Remote Sensing and GIS Techniques for Selecting a Sustainable Scenario for Lake Koronia, Greece, Environmental management, 2007, Vol. 39, No. 2, pp. 278-290.

Baker, C., Mapping Wetlands and Riparian Areas Using Landsat ETM+ Imagery and Decision-Based Models, Wetlands, 2006, Vol. 26, No. 2, 465-474.

Blanco, P.D., Ecological site Classification of Semiarid Rangelands: Synergistic Use of Landsat and Hyperion Imagery, International Journal of Applied Earth Observation and Geoinformation, 2014, Vol. 29, pp. 11-21.

Data Using N-Dimensional Geometry and a Mixture-Tuned Matched Filtering Approach, IEEE Transactions on Geoscience and Remote Sensing, 2011, Vol. 49, No. 11, pp. 4152-4138.

El Gammal, E.A. and Salem, S.M., Change Detection Studies on the World's Biggest Artificial Lake (Lake Nasser, Egypt). 
The Egyptian Journal of Remote Sensing and Space Science, 2010, Vol. 13, No. 2, pp. 89-99.

Fenster, M.S., Dolan, R. and Elder, J.F., A New Method for Predicting Shoreline Positions from Historical Data, Journal of Coastal Research, 1993, Vol. 9, No. 1, pp. 147-171.

Ghaheri, M., Baghal Vayjooee M. and Naziri, J., Lake Urmia, Iran: A Summary Review, International Journal of Salt Lake Research, 1999, Vol. 8, No. 1, pp. 19-22.

Hinton, J., GIS and Remote Sensing Integration for Environmental Applications, International Journal of Geographical Information Systems, 1996, Vol. 10, No. 7, pp. 877-890.

Mui, J.K. and Fu, K.S., Automated Classification of Nucleated Blood Cells using a Binary Tree Classifier, IEEE Transactions on Pattern Analysis and Machine Intelligence, 1980, Vol. 5, pp. 429-443.

Rebelo, L.M., Finlayson, C. and Nagabhatla, N., Remote Sensing and GIS for Wetland Inventory, Mapping and Change Analysis, Journal of Environmental Management, 2009, Vol. 90, No. 7, pp. 2144-2153.

Richards, J. A., Remote Sensing Digital Image Analysis, 2013, Springer Verlag.

Stappen, G., Fayazi, G. and Sorgeloos, P., International Study on Artemia LXIII. Field Study of the Artemia Urmiana Population in Lake Urmiah, Iran in Saline Lakes, 2001, Springer Verlag. pp. 133-143.

Swain P.H., H.H., The Decision Tree Classifier: Design and Potential, Geoscience Electronics.1977. Vol. 15, pp. 142-147.

Thies, B. and Bendix, J. , Satellite-Based Remote Sensing of Weather and Climate: Recent Achievements and Future Perspectives, Meteorological Applications, 2011, Vol. 18, No. 3, pp. 262-295.

Wasige, J.E., Monitoring Basin-Scale Land Cover Changes in Kagera Basin of Lake Victoria using Ancillary Data and Remote Sensing, International Journal of Applied Earth Observation and Geoinformation, 2013, Vol. 21, pp. 32-42.

Xiuwan, C., Using Remote Sensing and GIS to Analyse Land Cover Change and its Impacts on Regional Sustainable Development, International Journal of Remote Sensing, 2002, Vol. 23, No. 1, pp. 107-124.

Zhang, B., Estimation and Trend Detection of Water Storage at NamCo Lake, Central Tibetan Plateau, Journal of Hydrology, 2011, Vol. 405, No. 1, pp. 161-170. 